\title{
Ecofriendly Organosolv Process for Pulping of Tender Coconut Fibre
}

\author{
Jincy P.J. ${ }^{1}$, Anita Das Ravindranath ${ }^{2}$ and U.S. Sarma ${ }^{3}$
}

\begin{abstract}
The huge biomass generated by vendors of tender coconut is the broken husks refuse dumped along roads and highways in Kerala. These dumps become breeding grounds for diseased causing germs and carrier mosquitoes causing threat to human life. In order to avoid pollution and find use of the rejected biomass of tender husks, a study was carried out on pulping of tender coconut husk fibre which could be used for papermaking. The optimum pulping condition, the quality of the pulp and its yield was evaluated using different variables like time and temperature. It was observed that the organosolv process could efficiently remove lignin from the tender coconut fibre yielding maximum cellulose. During the traditional pulping processes such as Kraft pulping to isolate the cellulose fibers for the production of paper, the hemicellulose and lignin fractions are degraded, limiting their valorization possibilities. Organosolv pulping has been advocated as the environmentally benign version of the kraft process. Unlike other pretreatment methods, organic solvents can easily be recycled and reused. The lignin dissolved by organosolv pulping is easily recovered by dilution and is unsulphonated and relatively unmodified. Products like handmade paper, egg cartons, handicraft items, garden articles like paper pots could be made from the organasolv pulp of tender coconut husk fibre.
\end{abstract}

Keywords: tender coconut, organosolv pulping, morphology, handmade paper, organosolv lignin

\footnotetext{
${ }^{1}$ Department of Environmental Engineering, National Chung Hsing University, Taichung 402, Taiwan, ROC. Email: jincycusat@gmail.com

${ }^{2}$ Microbiology Department, Central Coir Research Institute, Kalavoor P.O, Alleppey Dist, PIN-688522 Kerala, India. Email: anitadas30@gmail.com

${ }^{3}$ Ex-Director, Research (RDTE), Central Coir Research Institute, Kalavoor P.O, Alleppey Dist, PIN-688522

Kerala, India. Email: uss_2000@yahoo.com
} 


\section{Introduction}

The coconut palm (Cocos nucifera), an important member of the family Arecaceae (palm family) is a tropical tree that is cultivated in nearly 90 different countries (Pires et al. 2004). It is estimated that out of total production of coconuts in the country $10 \%$ are plucked as tender coconuts. The water of the tender coconut, technically called the liquid endosperm, is enjoyed by people in tropical regions of the world, especially in Tropical Asia as well as Central and South America. It was discovered that this water has medicinal characteristics as an antioxidant, replenish fluid hydration, provide parenteral nutrition, etc. Despite its benefits, the market for coconut water causes solid waste environmental problems and is one of the major agro-industrial waste generators in some developing countries. It is a lignocellulosic material which is resistant to easy decomposition due to its high lignin content and causes environmental pollution. The husk containing about $80-85 \%$ moisture acts as breeding sites for insectsmosquitoes, flies etc. With the objective of utilization of the tender coconut huskagrowaste and reducing the environmental impact of its disposal, an ecofriendly organosolv process for pulping of tender coconut fibre could be developed.

Tender coconut fibre is a lignocellulosic material and is composed of carbohydrate polymers (cellulose and hemicellulose), lignin and a remaining smaller part (extractives, acids and salts and minerals). Cellulose is a polymer composed of chains of six carbon sugars (primarily glucose). These chains are bundled into strong fibers that on close inspection are seen to have an organized crystalline structure. Lignin is a complex, three dimensional polymer composed of linked six-carbon phenolic rings with various carbon chains and other chemical functionalities. Lignin is non-crystalline, and its structure has been described as analogous to a gel or foam. The lignin serves to bind the cellulose fibers. It is degradable by only few organisms, into several higher value products such as organic acids, phenols and vanillin. Via chemical processes valuable fuel additives may be produced. Hemicellulose is a very complex polymer composed of mainly xylose (fivecarbon) and further arabinose (five- carbon), galactose, glucose and mannose (all six carbon); it also contains smaller amounts of non-sugars such as acetyl groups. Hemicellulose, because of its amorphous nature, is relatively easy tohydrolyzes. Hemicellulose attaches weakly to both cellulose and lignin and fills the intervening spaces. Extractives are non-structural components of biomass samples that is soluble either in water or ethanol. It includes, but is not limited to sucrose, nitrates, nitrites, protein, chlorophyll, and waxes (fatty acids). The ash content is a measure of the mineral content and other inorganic matter in biomass.

Regardless of the application of lignocellulosic materials, it is required a preliminary processing to separate the three macromolecular fractions, particularly the lignin, which can be considered the main physical barrier for making the fibers (mainly cellulose) cemented together. These processes modify the lignocellulosic material by disruption of cell wall structure of plant biomass, removing, solubilizing or depolymerizing lignin. The kinds of processes depend on the material used and the proposed purpose of lignocellulosic fractions utilization and may be mechanical, physical, biological or chemical. The development of pretreatment processes strong enough as to separate the cell wall arrangement and mild enough as to avoid a significant chemical degradation of biomass components is a challenge for today's chemical industry (Canetieri et al, 2007). For the novel pretreatment methods it is advisable to use cheap and easily recoverable chemicals and low-cost equipment. The use of environmentally friendly and low energy-intensive approaches is highly desired. The chemical cooking process is the most efficient and most used to perform the separation of lignocellulosic components of vegetal biomass (Fernandez, 1996). It results in enlargement of the inner surface area of substrate particles, accomplished by solubilization and/or degradation of hemicellulose and lignin.

The shortage of raw materials and the large energy and water consumptions are presently the main concerns of pulp and paper 
industry. Considerable research effort has been made to introduce alternative species as raw materials, like biomass from agricultural and forestry residues. Organosolv processes were experimented based on the use of organic solvents as delignification agents, to degrade the lignocellulosic biomass to obtain cellulose fibers for paper making, high quality hemicelluloses and lignin degradation products avoiding emissions and effluents. Organosolv pretreatment has been evaluated as an effective pretreatment method for high lignin lignocellulosic biomass. The treatment can break down internal lignin and hemicellulose bonds and thus remove all of the lignin from biomass. A strong inorganic acid is usually applied in the organosolv pretreatment as a catalyst to hydrolyze the lignin-lignin and lignincarbohydrate bonds in biomass. Inorganic acids including hydrochloric acid, sulfuric acid and phosphoric acid have been frequently chosen. Generating high quality lignin is one of the unique advantages of the organosolv pretreatment over alternative methods, such as steam explosion, dilute acid treatment and hot water treatment, where the only proposed use for the lignin is as a boiler fuel. The organosolv spent liquor mixed with water could precipitate the dissolved lignin. In contrast to lignin produced by other technical processes, such as Kraft pulping, organosolv lignin is a sulfur free, low molecular weight product of high purity. High quality lignin can be used as a substitute for polymeric materials, such as phenolic powder resins, polyurethane foams and epoxy resins $(\mathrm{Li}$ et al, 2012). The other main advantages of the organosolv processes over the conventional ones are the following: low environmental impact, higher pulp yield, ease of bleaching, easy solvent recovery, low capital for a new plant and recovery of lignin and sugars for profitable utilization (Saberikhah et al, 2011).

In this investigation, the feasibility of an organosolv pulping process for the production of pulp from depithed tender coconut husk fiber was evaluated. Acetic acid was selected as an organic solvent for tender coconut husk fibre pulping, considering the results obtained in preliminary experiments and due to its easy availability. In the present study, a $70 \%$ aqueous solution of acetic acid was selected for tender coconut fibre pulping. Dilute sulfuric acid was applied as the catalyst for organosolv pulping. The effect of cooking time and temperature on pulp properties like yield, Kappa number and \% delignification were investigated. The bleaching ability of organosolv pulp by totally chlorine free (TCF) bleaching using alkaline hydrogen peroxide was also examined.

Conventional methods of bleaching involve treatment with molecular chlorine or chlorine based chemicals. Effluent from these processes produces large amounts of chlorinated organic compounds and releases into the environment. The interest in totally chlorine free bleaching processes has led to the development of peroxide based bleaching. One of the biggest advantage of hydrogen peroxide is that it is environmentally friendly throughout its whole life cycle. The perhydroxyl anion (HOO-) is the principal active agent in peroxide bleaching. This anion is a strong nucleophile which during bleaching converts electron rich chromophores to their non chromophoric counterparts. The reaction of lignin with peroxide is not reversible and lead to the permanent removal of most of the chromophoric groups in the lignin molecule (Presley and Hill, 1996).

\section{Materials and methods}

\section{Substrate preparation}

Tender coconut husk used in this work was collected from the local vendors in Alleppey district. Husk was depithed using shredder and the fibers were separated. After the separation of fiber from pith, the fibers were chopped into uniform sized pieces and air dried. The fibre had an average moisture content of $11.7 \%$.

\section{Chemical analysis of tender coconut fibre}

The specimens were sampled and characterized according to the standard methods. Chemical composition, given on an oven dry weight basis, was the following: $27.02 \%$ Cellulose (Uppdegraf, 1969), 56.82\% Holocellulose (ASTM D1104-56(1978), 36.9\% Acid insoluble lignin ( TAPPI T 222 om-98), $3.62 \%$ extractives in alcohol-benzene (TAPPI 
$\mathrm{T} 204 \mathrm{~cm}-97$ ) and $3.1 \%$ Ashes at $525^{\circ} \mathrm{C}$ (TAPPI T211 om-02).

\section{Organosolv pulping of tender coconut fiber}

Organosolv pulping involves contacting a lignocellulosic feedstock with an aqueous organic solvent at temperatures ranging from $140^{\circ} \mathrm{C}$ to $220^{\circ} \mathrm{C}$. This causes lignin to break down by hydrolytic cleavage of alpha aryl-ether links into fragments that are soluble in the solvent system. So in order to achieve high temperature, acetic acid cooking was performed under different conditions in a laboratory pulping unit provided with six autoclaves, each of 2.5 liter rotate in a heated poly glycol bath. The ratio of liquor/ fibre, acetic acid and $\mathrm{H}_{2} \mathrm{SO}_{4}$ catalyst concentration was maintained constant at $10: 1,70 \%$ and $0.5 \%(\mathrm{v} / \mathrm{v})$ respectively. Pulping was done at four temperatures $\left(150^{\circ} \mathrm{C}\right.$, $160^{\circ} \mathrm{C}, 170^{\circ} \mathrm{C}$ and $180^{\circ} \mathrm{C}$ ) and five cooking times $5,10,15,20$ and $25 \mathrm{~min}$ respectively at each temperature. After the digester was loaded with tender coconut fibre and cooking liquor, the temperature was allowed to rise. The rising period to the operating temperature is maintained constant as 70 minutes. After pulping for different time intervals the digester was kept for $10 \mathrm{~min}$ before opening. The spent liquor was immediately separated from the pulp by filtering in order to avoid lignin precipitation. The resultant pulp was then washed with fresh corresponding acetic acid and finally with water and air- dried overnight. The performance of the pulping process was evaluated by Kappa number and yield. The Kappa number (TAPPI T236 cm$85)$ is the volume $(\mathrm{mL})$ of $0.1 \mathrm{~N}$ potassium permanganate solution consumed by $1 \mathrm{~g}$ of oven dry fibrous material under the conditions specified in this standard method.

\section{Bleaching of organosolv pulp}

Bleaching of organosolv pulp was carried out using $15 \%$ hydrogen peroxide by weight of the dry pulp at a $\mathrm{pH}$ of 11.5 at 1: 15 solid to liquid ratio. $3 \%$ Sodium silicate was added to stabilize hydrogen peroxide. The material was treated for 4 hours at $80^{\circ} \mathrm{C}$. After treatment, the pulp was taken out, washed with cold water and air dried in the shade.

\section{Fiber morphology using Scanning electron microscopy (SEM)}

The changes in the morphology of the fibers were examined microscopically. For scanning electron microscopy (SEM) analysis, fiber was cut into small samples, mounted on stubs with adhesive, and then they were placed under vacuum, evacuated and sputter-coated with platinum using auto fine coater (JEOL JFC1600). After preparation of samples, the samples were observed under the Scanning Electron Microscope (JEOL JSM-6380LV).

\section{Thermal stability using thermogravimetric analysis (TGA)}

The thermal stability and decomposition analyses of the fibre and pulp were evaluated by thermogravimetric analysis (TGA) using a Mettler Toledo TGA/SDTA 851e Thermogravimetric Analyser. A sample mass of 2-3 mg were heated from $50{ }^{\circ} \mathrm{C}$ up to $700^{\circ} \mathrm{C}$ at a rate of $5^{\circ} \mathrm{C} / \mathrm{min}$ under nitrogen atmosphere in a constant flow of $80 \mathrm{~cm} 3 \mathrm{~min}-1$.

\section{Results and discussion}

\section{Optimization of organosolv pulping of tender coconut fibre}

The pulp yield, Kappa number, and \% delignification of organosolv pulp obtained from tender coconut husk fibre by different cooking conditions have been furnished in Figures 1,2 and 3 respectively.

The first assessment after any stage of lignocellulosic material treatment is the yield measurement (which is a parameter for the process classification). The total yield is measured as the ratio between the mass of material obtained after the treatment stage and the initial mass used to perform the same. (Candido et al, 2012).

The results indicate that the temperature and reaction time had a significant influence on delignification. It was found that with increase in temperature and time there was a decrease in pulp yield, Kappa number and residual lignin. However, it was seen that at all temperatures the 
delignification reactions were slow down after the initial 15 minutes reaction time.

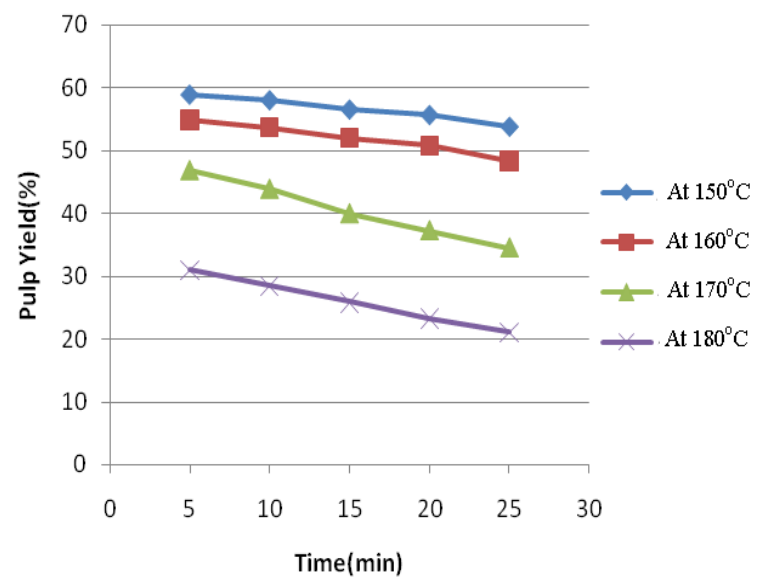

Figure 1. Effect of Temperature and Reaction Time on Pulp Yield

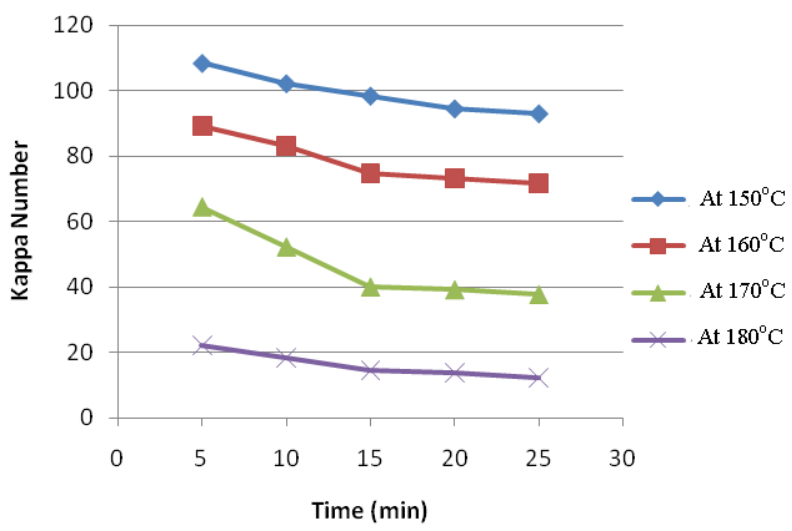

Figure 2. Effect of Temperature and Reaction Time on Kappa Number

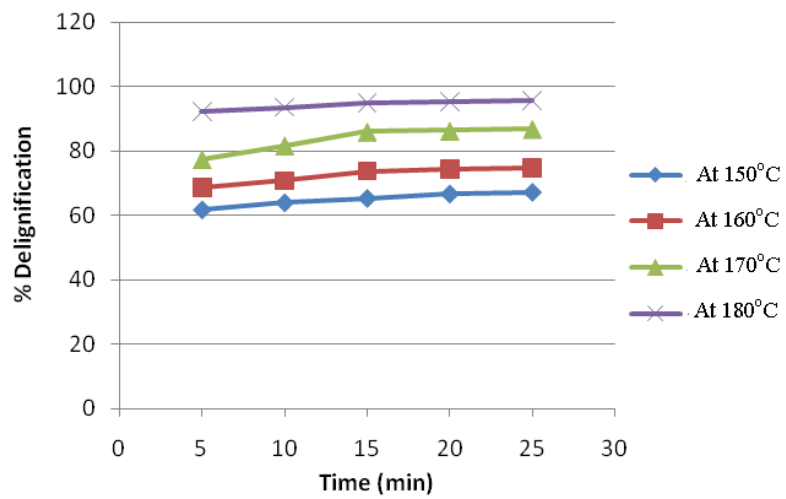

Figure 3. Effect of Temperature and Reaction Time on Delignification
It was seen that the pulping at $180^{\circ} \mathrm{C}$ resulted in an increased delignification. However the pulp yield was lowered to an unacceptable level. From the studies carried out it could be concluded that pulping at $170^{\circ} \mathrm{C}$ for 15 minutes was the most suitable condition for digestion of the fibre. Pulping at these conditions gave higher pulp yield and \% delignification with low Kappa number. When the reaction time increased from 15 to 25 minutes the delignification didn't increase significantly and the pulp yield was reduced from $39.94 \%$ to $34.49 \%$. The pulp yield at $180^{\circ} \mathrm{C}$ is very low compared to the pulp yield at $170^{\circ} \mathrm{C}$ which is undesirable for the pulp and paper production. Increase in reaction time from 5 to 25 minutes resulted in the decrease of pulp yield from 30.97 to 21.08 . This indicates that at higher temperature the loss of weight of tender coconut fiber was more due to the loss of more amounts of cellulose and hemicellulose content along with lignin.

Therefore, the optimum cooking conditions for a bleachable pulp of tender coconut husk fibre are as follows: acetic acid 70 $\%$, temperature $170^{\circ} \mathrm{C}$, cooking time 15 minutes and catalyst concentration $0.5 \%$. The pulp yield, $\%$ delignification and Kappa number values at this condition were $39.94 \%, 5.2$ and 85.91 respectively.

\section{Tender coconut fiber before and after organosolv pulping}

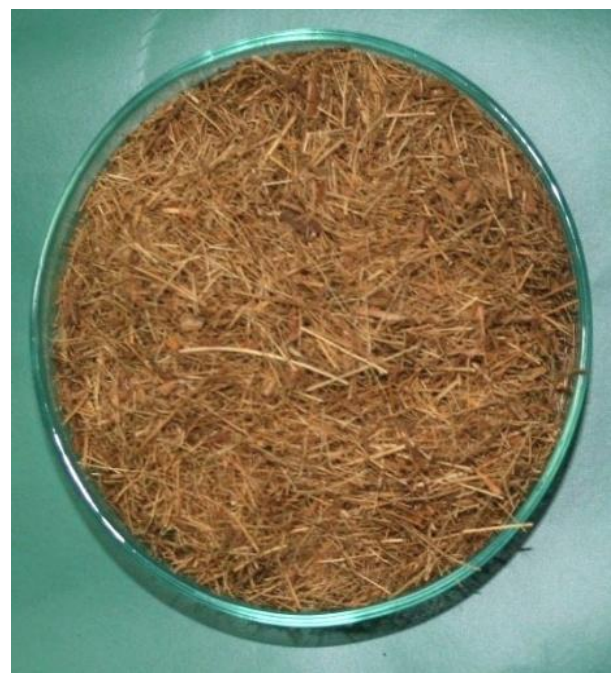

Figure 4. Raw fiber 


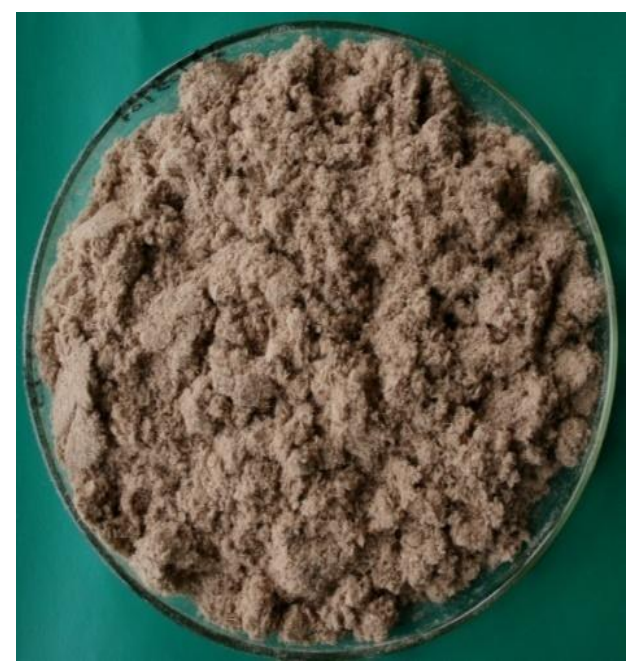

Figure 5. Fiber after organosolv treatment at $170^{\circ} \mathrm{C}$ and $15 \mathrm{~min}$

The material tends to get a dark colour after organosolv treatment (Figure 5) in contrast to raw fiber which is brown in colour (Figure 4). Therefore, the pulp has to be subjected to bleaching for acceptable brightness. In addition the structure of tender coconut fiber after organosolv treatment changed dramatically compared to the raw material (from fibers to a cardboard like appearance). The cellulose and hemicelluloses present in lignocellulosic fibers do not contribute significantly to coloration, due to their naturally white color characteristics. On the other hand, lignin and other extractives contribute to its darkness and therefore can be removed by bleaching.

After pulping, acetic acid can be regenerated from the black liquor by simple distillation and can be re-used in the cooking. The dissolved lignin and hemicelluloses in the acetic acid are collected as concentrated slurry after the distillation. The concentrated slurry is mixed with water, lignin is separated as precipitate and the hemicelluloses remain in water solution. The hemicelluloses are precipitated in ethanol. Therefore, we can utilize all the fractions of tender coconut in the acetic acid pulping.

Bleaching of the organosolv pulp was done by hydrogen peroxide. Physical and optical properties of the organosolv pulp were improved during hydrogen peroxide bleaching. After bleaching the pulp yield, \% delignification and Kappa number of the organosolv pulp at $170^{\circ} \mathrm{C}$ for 15 minutes was 92.6, 94.31 and 16.2 respectively.

\section{Surface morphology of tender coconut fibre and pulp}

Microscopic examination reveals that a single fiber comprises a bundle of multiple cells called ultimates. These ultimates in aggregate bundle are bound together by cementing materials like lignin and oriented roughly parallel to one another (Figure 6). The fibre shows globular structures in regular intervals (porous) and other constituents, probably organic residues (Mohanty and Nayak 2004; Ameida et al 2006) of the extraction of the fibres. The fibrils are covered by a cuticle layer, i.e. wax of aliphatic origin (Ratta 1999). Each cell is roughly polygonal in shape, with a central hole or lumen, comprising about $10 \%$ of the cell area of cross section.

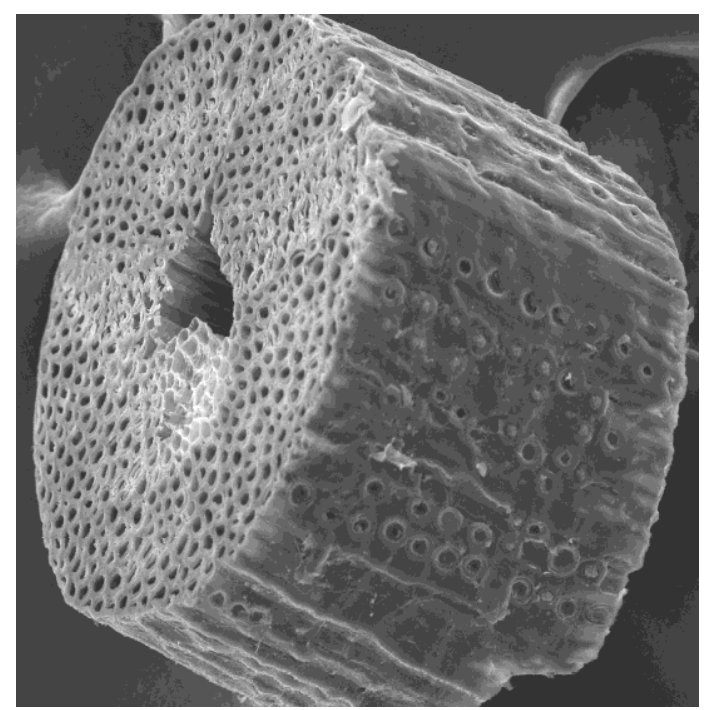

Figure 6. Cross-section of Raw coir fiber shown in SEM

After Organosolv treatment, the impurities and wax cuticle layers of the fibres surface were removed. The fibrils separate from each other due to removal of the lignin, the cementing component, by the action of the organic solvent, leading to an increase of the surface area (Figure $7 \mathrm{a}, \mathrm{b} \& d)$. 


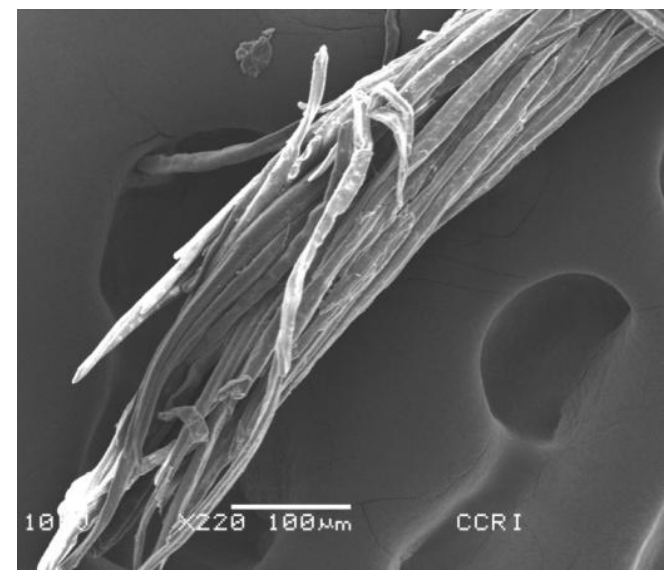

(a)

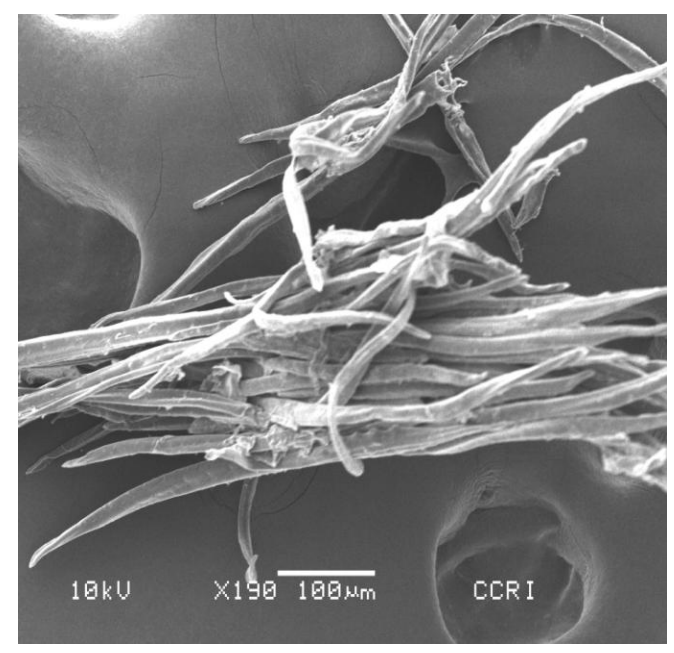

(b)

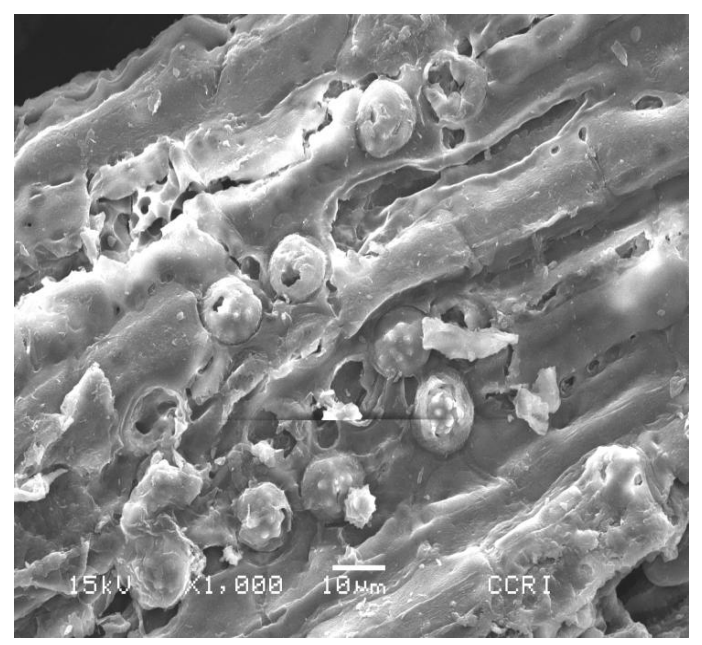

(c)

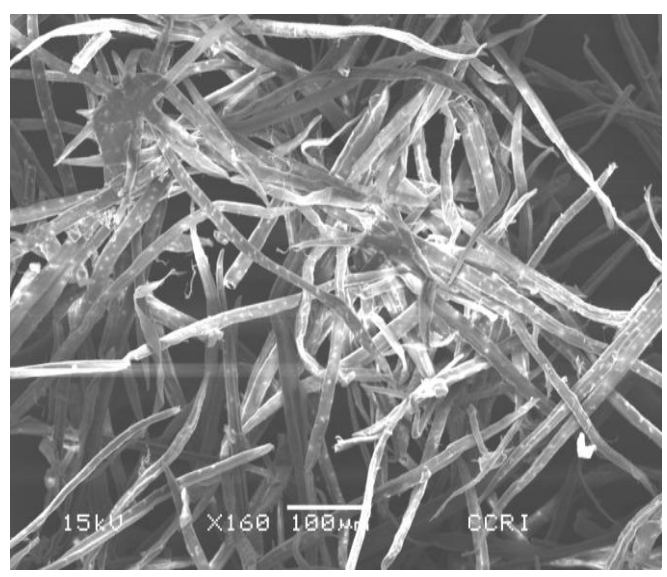

(d)

Figure 7. (a) \& (b) micrograph of fiber after organosolv pulping, (c) surface of the fiber after organosolv pulping, (d) micrograph of pulp after blending

The treatment also leads to changes in the hydrogen bonding interactions of hydroxyl groups of cellulose, resulting in the deformation of individual micro fibrils (Ganan and Mondragoni 2005). The treatment with acetic acid showed a more effective result in the lixiviation of the cuticle layer in removal of bonding material. Under this condition, the most external layer of the fibre was eliminated, revealing the fibrillar structures (Figure $7 \mathrm{a} \& b$ ). Grinding separates the individual fibers (figure 7 d). The surface morphology of the unbleached pulp (Figure 7 c) showed globular protrusions, identified as silicate stegmata. The cavities became more defined, and the surface fibres became rougher than in the untreated fibre.

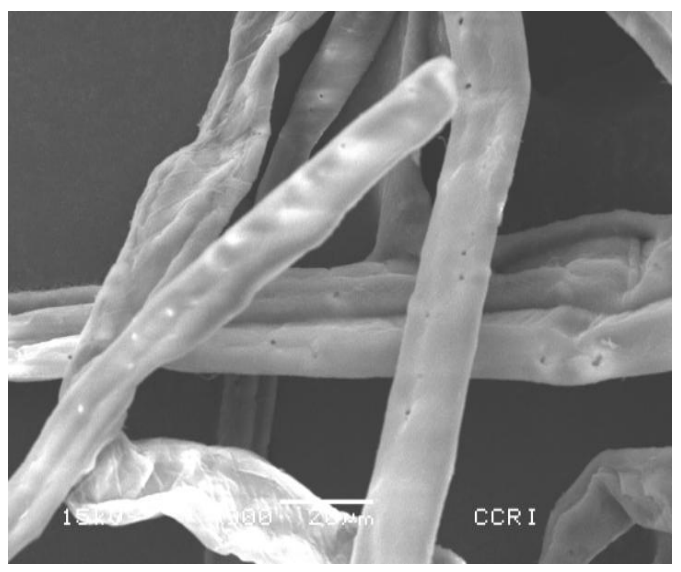

(a) 


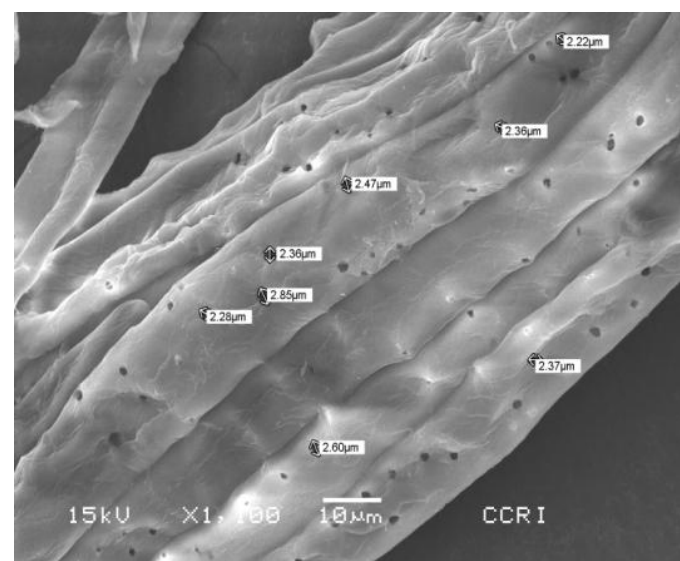

(b)

Figure 8. (a) \& (b) micrograph of the organosolv pulp after hydrogen peroxide bleaching

After hydrogen peroxide treatment the surface of the organosolv pulp was free of silica bodies, exposing the visible pits (Figure $8 \mathrm{a} \& \mathrm{~b}$ ). The surface became smoother than the unbleached pulp. The pits measured about 2.44 $\mu \mathrm{m}$ in diameter.

\section{Thermo gravimetric Analysis / Simultaneous Differential Thermal Analysis (TGA/SDTA) of raw fibre and pulp}

The thermo gravimetric (TG) and derivative of the thermogravimetry curve(DTG) curves for the raw tender coconut fibres and organosolv treated fibres are shown in Figure 9 and 10 . The results indicate that the range of thermal degradation decreased after organosolv treatment ( Karnani 2004, Mohanty 2000). The DTG curves show the first peak below $100^{\circ} \mathrm{C}$ as a result of evaporation of residual moisture. (Pothan et al. 1997; Pothan and Thomas 2003; Eichorn et al. 2001).

Thermal degradation in $\mathrm{N}_{2}$ atmosphere was characterized by an overlapping of processes that may occur in the same range of temperature, which can be separated only by observation of one of the peaks in the DTG output.

The treated fibre showed a single degradation peak in contrast to the double peaks observed in untreated fibres results. This is a further indication of a higher homogeneity resulting from organosolv treatment which also indicates that the macrocomponents were removed by the organosolv treatment. (Esmeraldo et al 2010).

The degradation in the treated fibres is attributed to the pyrolysis of cellulose and to residual hemicelluloses and this is shifted to lower temperature when the amount of lignin is reduced. Reported by Mitra et al (1998), Varma et al (1986) and Van Dam et al (2004) state that weight losses above $200^{\circ} \mathrm{C}$ can be attributed to the oxidation and condensation of carbohydrates, while the phenolic components of lignin are considered to be more stable. Also VazquezTorres et al (1992) after extraction and characterization of lignin samples from coconut fibre, verified that their decomposition starts from a temperature of approximately $380^{\circ} \mathrm{C}$.

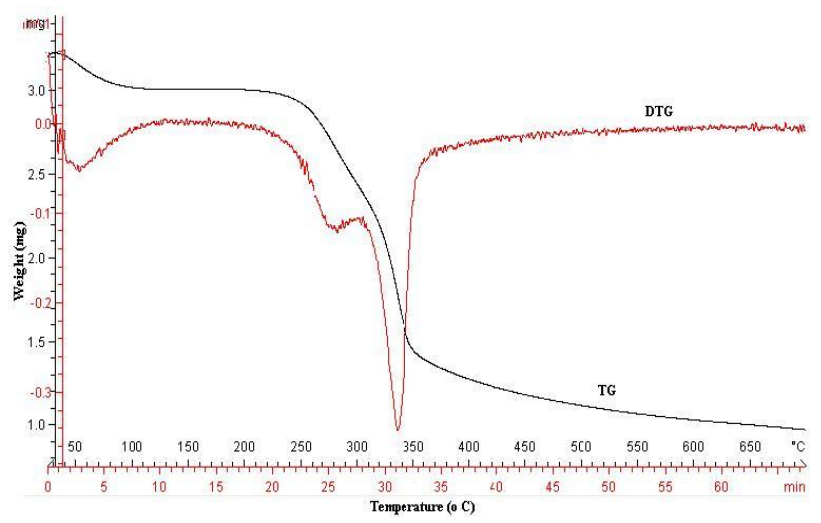

Figure 9. TG/DTG curve of raw tender coconut fibre

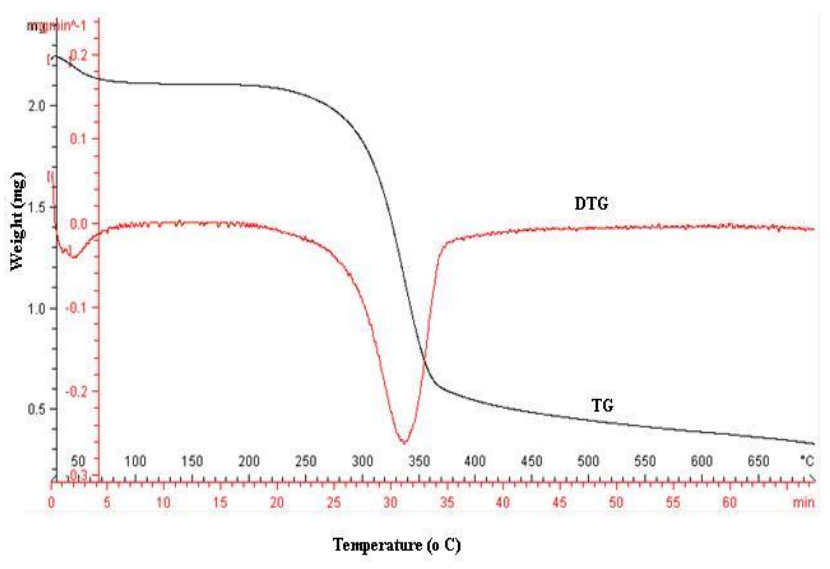

Figure 10. TG/DTG curve of organosolv pulp treated at $170^{\circ} \mathrm{C}, 15 \mathrm{~min}$ 


\section{Handmade papers and garden articles made from tender coconut husk organosolv pulp}

The organosolv pulp was diluted with water and then poured uniformly over a screen. The wet pulp was then transferred onto a cloth to remove the excess water. As the water drains out, the fibers come closer and closer together forming a tightly bonded mesh. The wet sheet was pressed to remove the remaining moisture. The pressed sheets were then laid on a smooth surface and dried under the sun. After the drying, calendaring of the handmade paper was done between stainless steel sheets. It was observed that blending bleached organosolv pulp with waste paper pulp in suitable proportions improves strength and surface smoothness of the handmade paper.

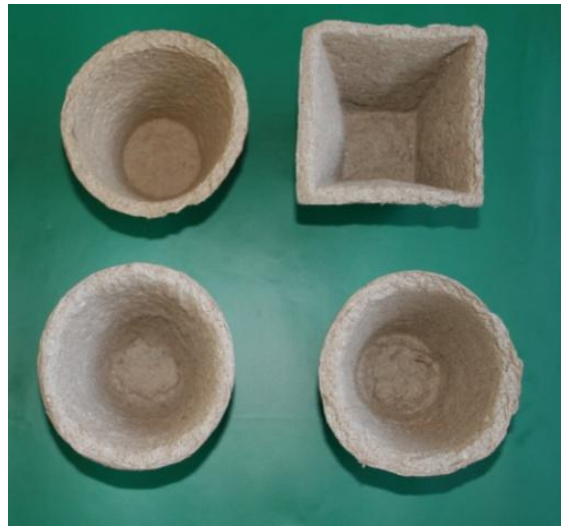

(a)

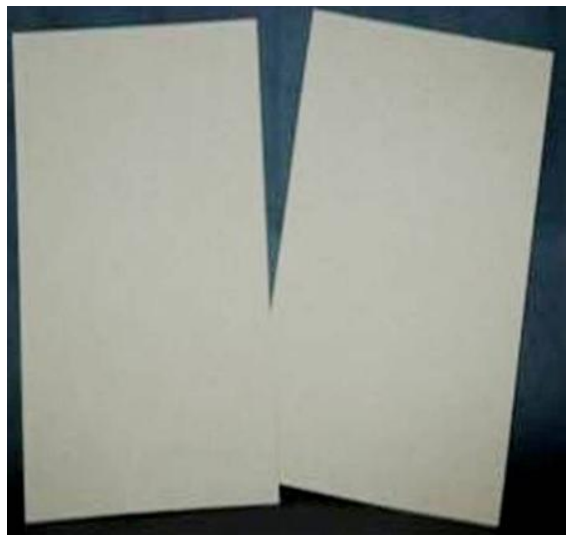

(b)

Figure 11. (a) Seedling pots made from unbleached organosolv plp, (b) Handmade paper made from bleached organosolv pulp
The pulp can also be moulded into various disposable articles like handmade paper, egg cartons, paper plates, cups, glass covers, garden articles like paper pots for seedling, and packaging materials.

\section{Conclusions}

The potential of tender coconut fibre for making diversified products by an ecofriendly organosolv process could be confirmed. Optimum digestion conditions to obtain a bleachable pulp of tender coconut husk fibre were as follows: using acetic acid $70 \%$, at a temperature of $170^{\circ} \mathrm{C}$ and cooking time 15 minutes in presence of a catalyst $(0.5 \%)$. The pulp yield, \% delignification and Kappa number values at this condition were $39.94,85.91$ and 40 respectively. After bleaching the \% delignification and Kappa number of the organosolv pulp has become 94.31 and 16.2 respectively. The drawbacks of kraft pulping relate to bad-odor problems, sulfur usage and bleaching problems could be eliminated considerably by applying the ecofriendly organosolv pulping processes. The recovery of the solvent from black liquor is easy and effective. Lignin is precipitated and can be separated from the black liquor after distillation. Therefore, complete utilization of the tender coconut husk fiber is possible by this environment friendly pulping method.

\section{Acknowledgment}

The authors gratefully acknowledge the financial support of the Coconut Development Board, Ministry of Agriculture, Government of India. Thanks are due extend to Prof. G. Balachandran, Ex-Chairman, Coir Board for his keen interest and guidance in this work.

\section{References}

Acid-insoluble Lignin in Wood and Pulp. TAPPI standard T 222 om-98.

Ameida, J.R.N.D., Aquino, R.C.M.P., and Monteiro, S.N. 2006. Tensile mechanical properties, morphological aspects and chemical characterization (Attaleafunifera) fibres, Composite Part A. Applied Science and Manufacturing 37 (9): 1473-1479. 
Ash in wood, pulp, paper and paperboard: combustion at $525^{\circ} \mathrm{C}$. TAPPI standard $\mathrm{T}$ 211 om-02

Candido, R.G., Godoy, G.G., Goncalves, A.R. 2012. Study of sugarcane bagasse pretreatment with sulfuric acid as a step of cellulose obtaining, World Academy of Science, Engineering and Technology 61:101-105.

Canetieri, E., Rocha, G.J.M., de Carvalho, J.R., Silva, J.B. 2007. A. Optimization of acid hydrolysis from the hemicellulosic fraction ofEucalyptus grandis residue using response surface methodology. Bioresource Technology 98(2):422-8.

Eichhorn, S. J., Baillie, C.A., Zafeiropoulos, N., Mwaikambo, L.Y., Ansell, M.P., Dufresne, A., P.J., Escamilla, G. C., Groom, L., Hughes, M., Hill, C., Rials, T. G. and Wild, P. M. 2001. Review: Current international research into cellulosic fibres and composites, Journal of Materials Science 36 (9):2107-2131.

Esmeraldo M.A., Antonio C.H. Barreto., Jose E. B. Freitas., Pierre B., A. Fechine., S.B. Sombra., Elisangela Corradini., Giuseppe Mele., Alfonso Maffezzoli and Selma, E. Mazzetto. 2010. Dwarf-green coconut fibers: a versatile natural renewable raw bioresource. Treatment, morphology, and physicochemical properties, Bio Resources 5 (4): 2478-2501.

Fernandez, N. 1996. Pulp and paper development from sugarcane bagasse. In: Third Internacional Non-wood Fiber Pulping and Papermaking Conference, Proceedings, Pequim (1):231-240.

Ganan, P., and Mondragon, I.2005. Effect of fibre treatments on mechanical behavior of short fique fibre- reinforced polyacetal composites. Journal of Composites Science and Technology 59(9): 1303-1309.

“Kappa Number of Pulp.” TAPPI Method T 236 cm-85

Karnani R., Krishnan M., Narayan, R. 2004. Biofiber reinforced polypropylene composites. Polymer Engineering and Science 37(2): 476-483.

Laly, A. Pothan., Sabu Thomas. 2003. Polarity parameters and dynamic mechanical behaviour of chemically modified banana fiber reinforced polyester composites. Composites Science and technology 63(9): 1231-1240.

Li, Yang ., Arthur, J. Ragauskas. 2012. Ethanol organosolv lignin-based rigid polyurethane foam reinforced with cellulose nanowhiskers. RSC Adv 2:3347-3351.

Method of test for holocellulose in wood, USA. 1978. ASTM D: 1104-56.

Mitra B.C., R.K. Basak, and M. Sarkar 1998. Studies on jute-reinforced composites, its limitations and some solutions through chemical modification of fibers. Journal of Applied Polymer Science 67(6):10931100.

Mohanty, K., M. Misra and G. Hinrichsen. 2000. Biofibres, biodegradable polymers and biocomposites: An overview. Macromolecular materials and engineering 276/277:1-24.

Mohanty, S., and Nayak, S.K. 2004. Effect of MAPP as coupling agent on the performance of sisal-PP composites. Journal Reinforced Plastics and Composites 23(18):2047-2063.

Pires, M., Costa, R.S., Jose', A.S., Badaro', M. M., Midlej, C., Alves, J.M. 2004. A cultura do coco: umaana' liseecono^ mica (The coconut culture: an economical evaluation). Rev. Bras. Frutic. 26(1): 173176.

Pothan L.A., Thomas, S., N.R. Neelakantan. 1997. Short Banana Fiber Reinforced Polyester Composites: Mechanical, Failure and Aging Characteristics. Journal of reinforced plastics and composites 16(8): 744-765.

Pothan, L.A., Oommen, Z., Thomas, S., Dynamic mechanical analysis of banana fiber reinforced polyester composites 
2003. Compos. Sci. Technol. 63 (2), $283-$ 293.

Presley, J.R., R.T. Hill. 1996. The Technology of Mechanical Pulp Bleaching. In: Peroxide Bleaching of Chemimechanical Pulps, Pulp Bleaching: Principles and Practice, Carlton W.D. and D.W. Reeve (Eds.). Chap. 1. TAPPI Press, Atlanta: 457-512.

R.C. Leitão, A. M. Arau' jo, M.A. Freitas-Neto, M.F. Rosa, S.T. Santaella. 2009. Anaerobic treatment of coconut husk liquor for biogas production. Water Science \& Technology-WST, 59(9):18411846.

Ratta, V. 1999. Thesis on the crystallization, morphology, thermal stability and adhesive properties of novel high performance semi crystalline polymides. Faculty of Virginia Polytechnic Institute and State University, Virginia.

Saberikhah E., J. Mohammadi Rovshandeh., P. Rezayati-Charani. 2011. Organosolv pulping of wheat straw by glycerol. Cellulose Chemistry and Technology, 45(1-2):67-65.

Solvent extractives of wood and pulp. (Proposed revision of TAPPI T $204 \mathrm{~cm}-97$ )

Uppdegraf . 1969. Semimicro Determination of Cellulose in Biological Materials. Analytical Biochemistry 32:420-424

Van Dam, J.E.G., Van Oever, M.J.A., Wouter Teunissen, Edwin R. P Keijsers, Aurora G Peralta. 2004. Process for production of high density/high performance binderless boards from whole coconut husk: Part 2: Coconut husk morphology, composition and properties. Industrial Crops and Products 19(3): 207-216.

Varma, D.S.,Varma, M., and Varma, I.K.1986. Thermal behavior of coir fibres. Thermochimica Acta 108:199-210.
Vasquez-Torres, H., Canche-Escamilla, G., and Cruz-Ramos, C.A.1992. Coconut husk lignin. 1. Extraction and characterization. Journal of Applied Polymer Science 45: 633-644.

Zhiqiang. Li, Zehui Jiang, Bengua Fei, Xunjun Pan, Zhiyong Cai, Xing'e Liu and Yan Yu. 2012. Bamboo organosolv pretreatment, Bioresources 7 (3): 3452-3462. 